matic colours which it had in the north disappear, and the whole mass, except under peculiar circumstances, looks like a motuntain of soda. At rare intervals, however, during a gorgeous sunset, the tinted clouds are reflected on its sides, and their various colours flash across like the shades of a rich shot silk, but infinitely more beautiful, eliciting terms of admiration alike from the sentimental dandy or the rough emigrant.

The cause of their early appearance so far south this spring is a mystery; many attribute it to a mild season. As I have before stated, I cannot concur in this opinion. No man can with certainty assert that in the Arctic regions a January temperature can cause the fracture of such masses from their original beds.

Celtic, July 28 WM. W. KIDDLE

\section{Science at Cambridge}

IN an article on the Public Schools Commission published in NATURE (vol. x. p. 219), the following passage occurs :- "Now it is acknowledged on all hands that the teaching of a subject at school and its recognition at the universities are inseparably connected, and especially with regard to science. The Colleges say, We cannot give more scholarships, because a sufficient number of men of good attainments do not present themselves; and the Schools reply, We cannot spend our time on subjects for which there are so few rewards. Both profess willingness, but each calls on the other to take the initiative." It is implied by this that the schools and universities each shelter themselves in their conservatism by throwing the blame on the other. With respect to the University of Cambridge, at least, I think this is unfair. King's College offered scholarships (of $80 \%$. a year for three years) for natural or physical science in the years 1872 and 1873 ; on both occasions the examiners (who were in no way connected with the college) reported that no candidates of sufficient merit had presented themselves. At length, in the present year, they have awarded a scholarship in these subjects.

Everyone who is conversant with Cambridge knows that the colleges are anxious to reward proficiency in science, and that the tendency is distinctly to award scholarships therein on easier terms than in other subjects, but that there is a dearth of candidates. Although the valuable science scholarships at Trinity have always been open to members of all colleges of either university, the number of those who have tried has always been very small.

I maintain, then, that Cambridge has taken the initiative as far as it is desirable to do so. It would be a lamentable thing to award prizes too profusely, as we should thereby be stocking the University with an inferior staff of teachers, who would transmit their inferiority to the succeeding generation.

Trinity College, Cambridge, July 30 GEORGE DARWIN

\section{Circulation of Apparatus and Scientific Works}

The letter of $\mathrm{Mr} . \mathrm{H}$. W. Lloyd Tanner (NATURE, vol. $\mathrm{x}$. p. 244) has opened up a subject of importance to all science teachers, and surely there are no insuperable difficulties in the way of the Kensington authorities sending out for loan, under proper conditions, apparatus and scientific works. Already there are loan collections of apparatus to be obtained from South Ken. sington by any recognised science class, but the cost of getting up and sending them out must be far greater than necessary. We were much amused last winter by receiving from the Department of Science and Art, as a loan, five huge boxes of elementary chemical apparatus. When these were opened we were quite disappointed, for only a few pieces proved useful in our class. We did not want a lot of big bell jars, glass retorts, Florence flasks, and bits of glass tubing stuck through wretched corks. Anyone can easily understand that it is simply waste of money to send to a science class apparatus on loan that the class already possesses. Why are not teachers allowed to choose the apparatus? In furtherance of the object mentioned by Mr. Tanner, may I be allowed to offer the following suggestions :-

I. That a collection of scientific apparatus and standard works for loan be made at Kensington.

2. That science teachers desirous of using books and apparalus pay a subscription, say, of ros. per annum.

3. That lists of apparatus and books be published, and sold to subscribers at a reasonable figure.

4. That books and apparatus (from list) be lent for a term to subscribers (subject, of course, to conditions of return in good order).
5. That the Department pay the carriage to and from Kensington.

Perhaps other readers of NATURE will kindly give further suggestions.

To such as myself, anything like the above would be a boon indeed. Living in a small country town in which there is neither public reading.room nor library, and being daily engaged in teaching science, and, withal, intensely fond of the study of it, I am thrown almost entirely upon my own resources to provide scientific books and apparatus. Yet I am better off than numbers of science teachers. The trustees of our schools have lately granted 57. a year for scientific apparatus, and to this we get the Government grant of 50 per cent. added. Further, I can at any time borrow a good microscope, and have access to several private libraries belonging to gentlemen of scientific tastes. Still, frequently, the very information wanted is not to be obtained, and I for one should be glad to avail myself of any scheme like the on $\epsilon$ I have suggested.

Dunstable

A. P. W.

\section{Sounding Flames}

IN the summer of $\mathrm{I} 842 \mathrm{I}$ attended the lectures of Dr. William Reid, brother of Dr. David Boswell Reid, the celebrated ventilator of the House of Commons, in the great barn-like classrooms of the latter chemist. In the practical class we produced sonorous flame vibrations in iron tubes three or four inches in diameter and about $2 \mathrm{ft}$. long, held over similar tubes covered with wire gauze. These instruments were the property of Dr. D. B. Reid, and produced a noise like the roar of a lion.
Edinburgh, Aug. 7
T. STRETHILL WRIGHT

\section{THE FRENCH ASSOCIATION FIOR THE AD.} VANCEMENT OF SCIENCE

THIS Association, as we have already intimated, meets at Lille on Aug. 20, and thus its meetings will be held contemporaneously with those of the British Association; this is perhaps to be regretted, as some of the members of the two Associations might wish to attend the meetings of both. The Lille session promises to be as brilliant as either of the two preceding ones. The proximity of Lille to Paris is very likely to attract a greater number of members than was gathered at Bordeaux or Lyons. A considerable number of foreigners have promised to "assist" at this year's meetiny ; among whom we notice the names of Prof. Sylvester and Dr. Odling.

The session will be opened at three o'clock on the afternoon of the 2oth, by the inaugural address of $\mathrm{M}$. Wurtz, the president for 1874, and also by an address by Lieut.Col. Laussedat, Professor at the Conservatoire des Arts et Métiers, general secretary of the Association for 1874 . There will, of course, be the usual sectional meetings, and several public lectures have been arranged for. Excursions always form an important part of the proceedings of the French Association, and three have been organised for this year ; the first excursion, on Aug. 23, will be to Boulogne ; the second on Aug. 25, to the coal-mines of the "Compagnie d'Anzin;" the third excursion commences on the 28th, after the conclusion of the meetings, and will probably be to Brussels and Anvers, lasting several days.

To show the magnitude to which this Association has already attained, we may state that about I50 names are down as readers of papers in the various sections, several of whom are to read more than one paper. M. Cornu is to describe a new optic spherometer. Several papers are to be read by M. Marcel Deprez on improvements in electrical apparatus and on certain theoretical aspects of steam-engines. Prof. Giard, of Lille, is to make several communications in Zoology, and $M$. Hamy in Anthropology; Prof. Houzeau, ot Rouen, is down for a paper on Concentrated Ozone ; and M. Lallemand, of Poitiers, will describe his researches relative to the Diffusion of Light. M. G. Lemoine will read two papers, one on 
researches in Chemical Mechanics, and the other on Equilibrium in Gaseous Systems. Prof. Terquem, of Lille, will read various papers in Optics and Acoustics, and M. G. Tissandier will give a public lecture on Meteorology and Balloons.

On the whole, there will be a fair number of purely scientific papers, though there is an unusually large proportion in medical and industrial subjects.

\section{THE COMETS}

THE following communication appears in the Times from Mr. J. R. Hind, F.R.S., dated Mr. Bishop's Observatory, Twickenham, August Io :-

"I send you positions of the last new comet (Borrelly) for the ensuing ten days; warning the amateur, however, that he must not expect to see it well without a very good telescope. They are deduced from the following orbit, which $I$ have calculated from the first accurate observation at Marseilles on July 26, one at Strasburg on Aug. I, received from Prof. Winnecke, and a third taken at $\mathrm{Mr}$. Bishop's Observatory on the 4th :-

"Perihelion passage, August, 27'086I Greenwich time; longitude of perihelion, $344^{\circ} 24^{\prime \prime} 6^{\prime \prime}$; ascending node, $250^{\circ}$ $59^{\prime} 50^{\prime \prime}$; inclination to ecliptic, $41^{\circ} 39^{\prime} 52^{\prime \prime}$; distance in perihelion, 0.98090 ; heliocentric motion, direct.

"The subjoined places are for midnight :-

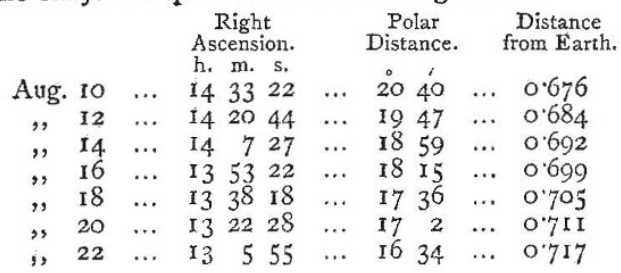

"The distances are expressed, as usual, in parts of the earth's mean distance from the sun.

"It appears that efforts in various observatories to obtain a daylight view of the late bright comet have been fruitless. I had been most hopeful of it being thus seen with the powerful telescopes and in the favourable climate of Marseilles; but I learn from M. Coggia that a close search for the comet in fine skies on July 22, and from morning to evening on the $26 \mathrm{th}$, failed to afford a glimpse of it. At Twickenham, under very advantageous circumstances, about noon on July 23 , we could not detect it, when Procyon, the principal star in Canis Minor, at nearly the same angular distance from the sun, was shining brightly in the telescope. It affords additional evidence that proximity to the earth is not so important a condition for visibility of a comet in the daytime as close approach to the sun; but it was very desirable to have the appearance of Coggia's comet upon record."

\section{THE FORM OF COMETS*}

IV.

$\mathrm{W}$

E have seen then that the phenomena of the tails of comets can be explained even including their most complicated appearances. I now proceed to deal with other phenomena, for the best proof of the truth of a theory is its capacity to explain a multitude of details which were not at first considered. Examine in the figure (Fig. 8) which I recently showed you of Donati's comet, that singular dark portion which is seen in the axis of the tail to a very considerable distance from the nucleus, and say if that cylindrical space, void of matter, is not the effect of the interposition of a screen-the nucleus, which intercepts the repulsive force, and suppresses in this region all the nolecules driven from the head of the comet. This is

\footnotetext{
* Continued from $\mathrm{p}, 270$.
}

because the repulsive force, being a surface-action, is spent against that of the nucleus, and is arrested by this simple screen ; it is quite the reverse of attraction, which acts effectually through all matter as it that matter did not exist. This cannot have been the shadow thrown by the nucleus, for two reasons, of which it is enough to mention the first : the black streak, besides being much too long, is not in the exact direction of the luminous ray; it is inclined to the radius vector at an angle of several degrees, for which the theory accounts. In short, it widens considerably when tails almost straight, composed of the rarest materials, are about to disappear, and we can often follow its trace to the extremity of the tail.

But I must dwell, in conclusion, upon the curious phenomena of the head and upon the luminous sectors which usually appear in the direction of the sun. We find here a new confirmation of the play of the repulsive force. Fig. I 5 is a drawing on a large scale of the head of the comet of I86r, made at Rome by Father Secchi.

Let us not forget, in what follow's, that one of the characteristic features of the nebulous layers which surround the nucleus, and of which it is perhaps entirely composed, is the transparency which permits us to see small stars through depths much greater than that of our atmosphere. There is reason, then, for believing that the solar ray's penetrate across these layers to the central nucleus and heat it, all the more since these same layers are probably not so permeable to dark heat as they are to luminous heat. In the space of three weeks the central heat may thus be raised from the degree of heat of distant space to a temperature sufficiently elevated to volatilise a part of the matter of the nucleus, and perhaps promote chemical reactions arrested till then by the original cold.* Under this increasing influence the matter is dilated and rapidly separates from the nucleus (I9 metres per second for Donati's comet); but soon this matter, still too dense to be sensibly repelled, reaches the surface limit beyond which it ceases to belong to the comet. This surface limit presents, as we have seen, two opposite conical points by which the emission takes place. At a later period this matter getting further and furtber away, and becoming more and more rarefied, falls under the action of this repulsive force, which then makes it turn tail and fly to the rear. This species of conical envelope, turned towards the sun, assumes the appearance of a calyx with inverted edges, while the opposite envelope with obscure interior contracts under the influence of the same action, but without changing its curvature. There will be noticed, in front of this species of calyx, exterior strata nearer to the sun, to which they present their convexity instead of being opened out conformably to the theory which M. Roche had hitherto based solely upon attraction. I asked $M$. Roche to introduce the new force into his investigation of the surfaces assumed by a fluid mass submitted to the double attraction of its own mass and of that of the sun, and we have had the satisfaction of seeing one of the two singular points of the surface limit disappear. The surfaces are completely enclosed and become curved towards the sun; there is no room on this side for any loss of matter. But this is to be expected in the exterior layers, which have too little density to obey repulsion; while in the interior of the head, very near the nucleus, attraction still rules exclusively on account of a density still very great.

In order to render these somewhat complicated de tails of the theory intelligible, we have only to turn round on its axis Fig. I6; it will generate a surface of revolution composed of an exterior envelope having a form roughly parabolic, and of two envelopes attached to the

* Spectrum analysis seems to prove that this heat may reach the point of giving to the nucleus a light of its own, presenting, moreover, the characteristics of a light emitted by a gaseous substance. But up to the present time ( 1870 ), indications of this kind are too vague and too doubtful to enable us to derive much help from them. 